\title{
Control of salt water intrusion due to sea level rise in the coastal zone of Bangladesh
}

\author{
M. J. A. N. Bhuiyan \& D. Dutta \\ School of Applied Sciences and Engineering, Monash University, \\ Australia
}

\begin{abstract}
One potential impact of a global warming and rise in sea level would be an increase in the salinity of coastal zones, which would potentially threaten drinking water and aquatic ecosystems. There is a need to be better prepared to respond and adapt to these changes. This report examines the potential impacts of accelerated sea level rise on salinity in the South West region of Bangladesh. The study aims at determining the sensitivity of river salinity to upstream discharge and downstream sea level. To do that, the minimum upstream flow will be determined to protect the salinity intrusion from sea level rise. A one dimensional river salinity transport model has been developed and coupled with an existing surface and river flow model. The model has been proved to be robust with calibration and verification against observed data. The model outputs indicate a significant change of river salinity in the coastal zone. The results also indicate that a considerable advance in seawater intrusion can be expected in the coastal aquifer if current rates of sea level rise continue. The topography of the area is flat and gently sloping towards the Bay of Bengal. The consequences of salinity intrusion in the coastal area especially in the South West region of Bangladesh would be significant on many sectors like land fertility, agriculture, availability of fresh water, existence of the Sundarban forest etc. Pond culture in the coastal area will be affected by intrusion of salt water into ponds, unless embankments are made around them. Shrimp culture in the coastal area is a lucrative business. Increase in salinity is likely to jeopardize the shrimp culture. Keywords: flow, river, salinity, salt water intrusion, sea level rise.
\end{abstract}




\section{Introduction}

One of the future challenges from climate change is the sea level rise and its effect on salt water intrusion. The coastal zones of Bangladesh are threatened by salt water intrusion due to tidal impact from existing sea level. The intrusion length is increasing as the climate is changing and corresponding sea level rise (SLR). The coastal zones of Bangladesh, especially the South West region is the worst to be affected by sea level rise. The current rate of sea level rise will shift the saltwater further upstream in the coastal river. Bashar and Hossain [1] found that the situation is worsening with low river flow because of upstream withdrawal, increase usages and subsidence. As a result, it is becoming a great challenge to supply required fresh water to the coastal rivers. The adjacent aquifer will be contaminated through leakage from the river water. Existing fresh water fishes will migrate and decrease the availability. Therefore, saltwater intrusion due to sea level rise should be predicted and necessary measures need to be taken to prevent this intrusion.

A vast network of rivers in the South West region of Bangladesh is dependent on the water supply through the Gorai River, fig. 1. Water from this river is used for irrigation, urban water supply and industry. Most importantly, the Gorai river flow opposes away the saline water front in the Passur river. Monsoon flow is adequate for repelling the salinity intrusion but the dry season flow is most critical in controlling salinity in a large part of the South West region of Bangladesh.

Considerable attention has been focused on mathematical models to study the salt water intrusion and developed scenarios to control the intrusion. Various models have been developed to investigate salt water intrusion. However, only few models have been developed to study the control of salt water intrusion. This paper will discuss the salinity intrusion in the South West region of Bangladesh. Also the study will be used to analyse the position and movement of salinity front line and suggest new methodology to protect salt water intrusion. Here, the scenario used is the increased upstream river fresh water discharge.

\section{Location and geomorphology}

The study area covers part of the Ganges river basin which is located in the South West region of Bangladesh, fig.1. The area is bounded by the Ganges river in the north, Arial Khan-Bishakandia-Bishkhali river in the east, the Bay of Bengal in the south, and by the international boundary between Bangladesh and India in the west. The available data for analysis corresponds to 3 upstream river flow measuring stations, 4 river water level measuring stations and 2 river water quality measuring stations. The area is in a humid climate with an annual rainfall ranging from 1500 to $2100 \mathrm{~mm} ; 90 \%$ of which occurring in the wet season (May-Sept) (Nobi and Gupta [2]). The topography of the region shows land slope from north to south with low gradient so the stream flow in the river occurs from upstream river to the Bay of Bengal. Major part of the area is protected by the polders (embankment or levee) from river flooding. 
From the coastline, salt water intrudes into the river system and traversed few hundred kilometers towards the inland waters. The salinity level in the river water fluctuates seasonally depending on the amount of fresh-water flow. The river system is highly saline during low flow period in dry season. The GoraiMadhumati River, major augmenting river system reduces the flow during the dry season. Detail information about hydrogeological and meteorological data of the area of interest, such as salinity, soil type, rainfall are available in reports such as Nobi and Gupta [2], Haque [3], Mirza and Sarker [4] and Mondal et al. [5].

The region receives freshwater through two river system: Gorai-ModhumatiNabaganga and Kapotakshi-Sibsa (Figure 1). The southern part of the region is dominated by tidal river systems: Arpangasia, Sibsa, Passur and Baleswar. The tidal wave propagates into the region through these tidal rivers. These tidal rivers contribute salinity intrusion in the region. Fresh water flows from upstream rivers protect salinity intrusion and lower the salinity concentration. The river system of the region starts to be affected by sea salinity in November and reaches to a maximum in April and May (Mirza and Sarker [4]).

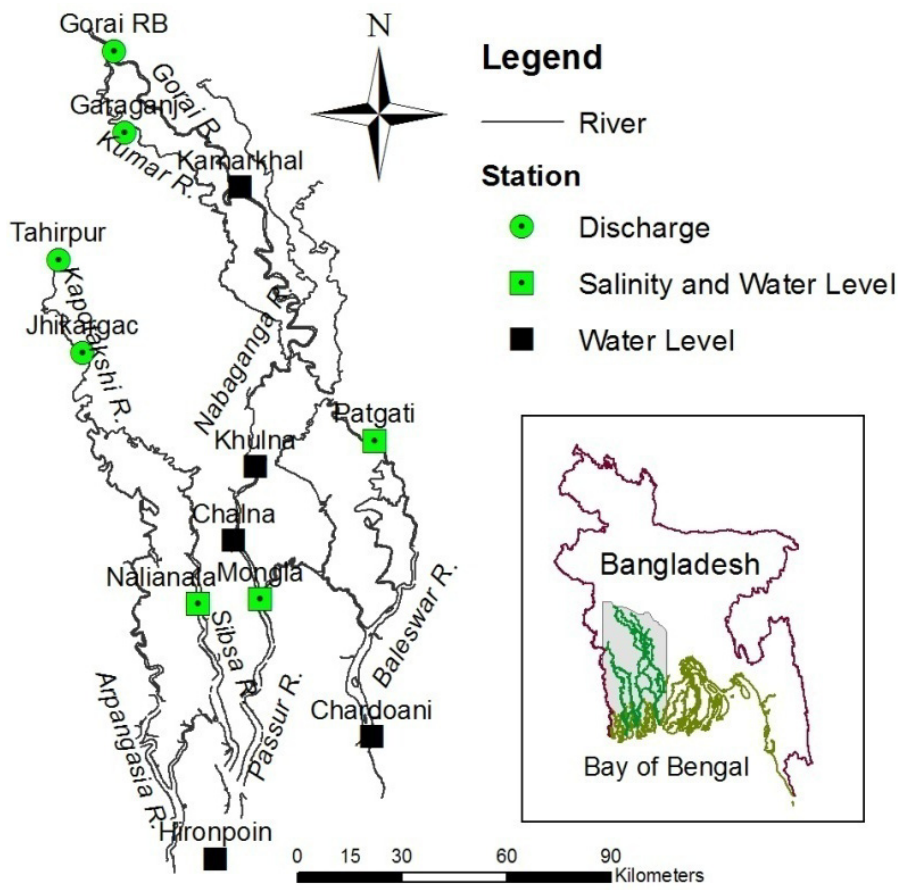

Figure 1: River network and stations in the South West region of Bangladesh.

\section{Mathematical model}

The mathematical model has been described here in two different sections; flow model and solute transport model. The flow model is a hydrodynamic model 
which comprises river and overland flow section. The salinity transport model computes salinity along with the river flow component.

\subsection{Hydrodynamic model}

The hydrodynamic model was originally developed at the Public Work Research Institute (PWRI) of Japan. The model has two components: river flow and overland flow. The model has been widely applied for flood modelling and risk analysis in Asian river system (Bhuiyan et al. [6]; Dutta and Bhuiyan [7]). For simulating surface flow processes, the study area is first discretized into square grids. Unsteady equations are derived from continuity and momentum equations for one dimensional as well as two dimensional flows. In river flow component, the finite difference equation for one dimensional channel flow is solved in each section of the channel for water level and discharge. It uses explicit solution scheme for river flow calculation. The form of momentum equation described in Dutta et al. [8] is as below;

$$
\begin{gathered}
A \frac{d Q}{d t}+Q^{2} \frac{d \beta}{d x}-2 \beta Q \frac{d A}{d t}-\frac{\beta Q^{2}}{A} \frac{d A}{d x}+g A^{2} \frac{d H}{d x}+\frac{A}{\rho} T_{r}=0 \\
T_{r}=\rho g A \frac{Q^{2}}{\left[\sum \frac{A}{n} R^{2 / 3}\right]^{2}}
\end{gathered}
$$

where $A$ is the river cross-section, $Q$ is river discharge, $T_{r}$ is river bottom shear, $H$ is water level, $R$ is hydraulic radius.

In overland flow component, fundamental equations of two dimensional unsteady flows are constructed from continuity equation and equation of motion. Equation 3 represents the continuity equation and equations 4 and 5 represent the equation of motion in $x$ and $y$ direction respectively (Dutta et al. [8]).

$$
\begin{gathered}
\frac{\partial h}{\partial t}+\frac{\partial M}{\partial x}+\frac{\partial N}{\partial y}=0 \\
\frac{\partial M}{\partial t}+\frac{\partial u M}{\partial x}+\frac{\partial v M}{\partial y}+g h \frac{\partial H}{\partial x}+\frac{1}{\rho} \tau_{x}(b)=0 \\
\frac{\partial N}{\partial t}+\frac{\partial u N}{\partial x}+\frac{\partial v N}{\partial y}+g h \frac{\partial H}{\partial y}+\frac{1}{\rho} \tau_{y}(b)=0
\end{gathered}
$$

where $H$ is the water level from datum, $h$ is depth of water, $u$ is flow velocity in $x$ direction, $v$ is flow velocity in $y$ direction, $g$ is gravitational acceleration, $\rho$ is density of water, $M$ is discharge flux in $x$ direction $(M=u h), N$ is discharge flux in $y$ direction $(N=v h), \tau_{x}(b)$ is bottom shear stress in $x$ direction, $\tau_{y}(b)$ is bottom shear stress in $y$ direction.

The main characteristic of the model is the link between unsteady calculation in river channel and calculation of flood in river basin to reproduce the flood inundation phenomenon in large scale over the whole river system. The relation 
between stages in river channel and height of levee decides the points and scale of flood over the levee with unsteady calculation in river channel.

\subsection{Salinity transport model}

A salinity transport model has been developed to investigate transport processes within the river system through estimating the advection dispersion process and coupled with the hydrodynamic model. The transport by dispersion of solute along the longitudinal direction involves a mathematical representation in the form of following one dimensional, partial differential equation (Fischer et al., [9]; Orlob [10]; Henderson-Sellars et al. [11]; Young and Wallis [12]), usually known by Fickian Diffusion Equation or Advection Dispersion Equation,

$$
\frac{\partial C}{\partial t}+v \frac{\partial C}{\partial x}=D \frac{\partial^{2} C}{\partial x^{2}}
$$

where $C$ is the concentration of the solute; $v$ is cross-sectional average longitudinal velocity; and $D$ is longitudinal dispersion coefficient. The dispersion coefficient can be specified as a function of the flow velocity calculated by the following equation,

$$
D=a v^{b}
$$

where $D$ is the dispersion coefficient, $v$ is flow velocity, $a$ is dispersion factor, $b$ is a dimensionless exponent. MIKE 11 model uses same concept when running advection dispersion simulation (DHI [13]).

The finite difference method is a well-established numerical method which has been used here to approximate the partial derivatives in equation 6 . If the concentration at a particular time step is calculated based on the concentration at previous time step and in approximating the advection and dispersion terms of the transport equation, the temporal discretization is said to be explicit, leading to the following form of the finite difference form (Zheng and Bennett [14]):

$$
\begin{array}{r}
C_{i}^{t+1}=C_{i}^{t}+\frac{D \Delta t}{(\Delta x)^{2}}\left(C_{i+1}^{t}-\right. \\
\left.2 C_{i}^{t}+C_{i-1}^{t}\right)-\frac{v \Delta t}{\Delta x}\left[(1-\alpha) C_{i}^{t}\right. \\
\left.+\alpha C_{i+1}^{t}-(1-\alpha) C_{i-1}^{t}-\alpha C_{i}^{t}\right]
\end{array}
$$

where $C$ is the salinity concentration; $i$ is river section; $t$ is time; $D$ is dispersion coefficient; $v$ is velocity, $\Delta x$ is distance between section, $\alpha$ is spatial weighting factor.

\subsection{Model setup}

The surface water system of interest is approximately $120 \mathrm{X} 269 \mathrm{~km}^{2}$, and is covered with a grid of $500 \mathrm{~m}$ square size in the model set up. The model contains 129120 cells: $n x=240$, ny $=538$, where $n$ denotes the number of cells, $x$ denotes East-West direction and y denotes North-South direction, fig.1. The model simulation time step to calculate surface flow is 2 seconds but the results have been compared with 3 hourly data. The existing polder heights have been used to 
protect against flooding in the surface. Here simulation result only from river flow model has been discussed but the combined river and surface flow model have been used for better performance and water budget calculation.

For this study, hydrological and salinity data were collected from a number of agencies in Bangladesh. Temporal scale discharge data were derived from the Institute of Water Modelling (IWM) data set. Station wide salinity during high and low tide for various periods have been supplied by the Bangladesh Water Development Board (BWDB). Salinity time series data has been collected from IWM, Dhaka, Bangladesh.

\subsection{Calibration and verification}

The combined model has been calibrated and verified against measured data at some selected stations in the river. The hydrodynamic model result has been compared against observed water level and salinity transport model against observed river salinity. The details of result comparison have been tabulated in Table 1. Here the water level unit is meter above PWD datum and salinity unit is parts per thousand. The PWD datum is $0.46 \mathrm{~m}$ below mean sea level (Tingsanchali and Karim [15]. Further details of time series data for different stations are available at Bhuiyan and Dutta [16].

Table 1: $\quad$ Summarized model results from calibration and verification.

\begin{tabular}{|c|c|c|c|c|c|c|c|}
\hline Model setup/ & Station & \multicolumn{3}{|c|}{ Observed } & \multicolumn{3}{c|}{ Model simulated } \\
\cline { 3 - 8 } Parameter & & Max & Min & Avg & Max & Min & Avg \\
\hline Calibration/ & Kamarkhali & 1.83 & 1.18 & 1.43 & 1.84 & 1.34 & 1.58 \\
\cline { 2 - 8 } Water level & Patgati & 1.8 & 0.38 & 1.18 & 1.88 & 0.36 & 1.09 \\
\cline { 2 - 8 } & Mongla & 2.5 & -1.6 & 0.52 & 2.39 & -0.94 & 0.56 \\
\cline { 2 - 8 } & Nalianala & 2.47 & -1.80 & 0.33 & 2.82 & -1.56 & 0.60 \\
\hline Verification/ & Kamarkhali & 2.87 & 1.72 & 2.30 & 2.86 & 1.77 & 2.33 \\
\cline { 2 - 8 } Water level & Patgati & 2.12 & 1.08 & 1.65 & 2.42 & 0.66 & 1.60 \\
\cline { 2 - 8 } & Mongla & 2.64 & -1.17 & 0.92 & 2.67 & -0.63 & 0.94 \\
\cline { 2 - 8 } & Nalianala & 2.98 & -1.40 & 1.06 & 3.01 & -1.03 & 1.06 \\
\hline Calibration/ & Mongla & 12.4 & 11.7 & 12.0 & 13.8 & 11.8 & 12.6 \\
\cline { 2 - 8 } Salinity & Nalianala & 19.4 & 15.7 & 17.7 & 19.8 & 15.6 & 18.1 \\
\hline Verification/ & Mongla & 15.1 & 9.4 & 13.4 & 14.6 & 11.3 & 13.2 \\
\cline { 2 - 8 } Salinity & Nalianala & 19.9 & 8.6 & 15.6 & 20.2 & 15.2 & 17.7 \\
\hline
\end{tabular}

The model performance has been checked using some statistical indicators, which have been summarized in Table 2. Here the indicators used are: relative root mean squared error (RRMSE); mean absolute error (ABSERR); the NashSutcliffe modeling efficiency index (EF); the goodness-of-fit $\left(\mathrm{R}^{2}\right)$ and the $\%$ of deviation from observed stream flow (PBIAS). The equations used when determining these indicators are taken from Stehr et al. [17]. The statistical indicators have been derived for water level and salinity at Kamarkhali, Patgati, Mongla and Nalianala station during calibration and verification period. The 
closer the values of RRMSE and ABSERR to zero, and those of $\mathrm{R}^{2}$ and EF to unity, the better the model performance is evaluated (Abu El-Nasr et al. [18]). For PBIAS, the optimal value is 0 ; a negative value indicates an overestimation of observed values, whereas a positive value indicates underestimation.

Table 2: $\quad$ Statistical analysis of model performance.

\begin{tabular}{|c|c|c|c|c|c|c|}
\hline $\begin{array}{c}\text { Model setup/ } \\
\text { Parameter }\end{array}$ & Station & PRMSE & ABSERR & EF & $\mathrm{R}^{2}$ & PBIAS \\
\hline $\begin{array}{c}\text { Calibration / } \\
\text { Water level }\end{array}$ & Kamarkhali & 0.14 & 0.15 & 0.32 & 0.43 & -11.04 \\
\cline { 2 - 7 } & Patgati & 0.18 & 0.16 & 0.62 & 0.79 & 8.11 \\
\cline { 2 - 7 } & Mongla & 0.68 & 0.40 & 0.78 & 0.80 & -7.91 \\
\cline { 2 - 7 } & Nalianala & 1.87 & 0.90 & -0.22 & 0.15 & -77.67 \\
\hline $\begin{array}{c}\text { Calibration / } \\
\text { Salinity }\end{array}$ & Mongla & 0.23 & 0.64 & -9.71 & 0.42 & -5.13 \\
\cline { 2 - 7 } & Nalianala & 0.22 & 0.74 & 0.35 & 0.81 & -2.56 \\
\hline Verification / & Kamarkhali & 0.05 & 0.06 & 0.97 & 0.96 & 1.42 \\
\cline { 2 - 7 } Water level & Patgati & 0.19 & 0.22 & -0.13 & 0.53 & 2.98 \\
\cline { 2 - 7 } & Mongla & 0.65 & 0.50 & 0.66 & 0.66 & -3.05 \\
\cline { 2 - 7 } & Nalianala & 1.12 & 0.96 & 0.01 & 0.16 & -0.21 \\
\hline \multirow{2}{*}{$\begin{array}{c}\text { Verification / } \\
\text { Salinity }\end{array}$} & Mongla & 0.29 & 0.89 & 0.53 & 0.57 & 2.29 \\
\cline { 2 - 7 } & Nalianala & 0.90 & 2.76 & 0.20 & 0.64 & -13.72 \\
\hline
\end{tabular}

The hydrodynamic model results at Kamarkhali are well calibrated and verified where the model computed water levels have been compared against observed values. The water level comparison at Patgati station shows very good correlation and good matching with observed level in phase and amplitude of tide. Tidal water level at Nalianala station shows poor correlation during low tide period but better during high tide. In spite of this discrepancy, the simulated salinity is close to the observed data at this station. Computed salinity at Patgati shows good match but due to limited number of observed data, calculation of statistical measures was not possible.

\subsection{Scenarios}

The combined model has been simulated for different scenarios to observe the sensitivity of river salinity to upstream discharge as well as downstream sea level. The following scenarios have been used;

Scenario 1: Present condition with no sea level rise

Scenario 2: Constant sea level rise of $59 \mathrm{~cm}$

Scenario 3: Same sea level rise with $200 \mathrm{~m}^{3} / \mathrm{s}$ discharge through Gorai river, $50 \mathrm{~m}^{3} / \mathrm{s}$ discharge through Kumar-Nabaganga River and $10 \mathrm{~m}^{3} / \mathrm{s}$ discharge through Kapotakshi River.

Scenario 4: Same sea level rise with $100 \mathrm{~m}^{3} / \mathrm{s}$ discharge through Gorai river, $10 \mathrm{~m}^{3} / \mathrm{s}$ discharge through Kumar-Nabaganga River and $5 \mathrm{~m}^{3} / \mathrm{s}$ discharge through Kapotakshi River. 


\section{Result analysis}

Salinity values were extracted from the simulated results for generation of salinity profile for different river system. Then the results for different scenarios were compared with that of current condition to determine the salinity changes at particular stations and salinity intrusion along particular rivers.

Salinity long profile along Kumar-Nabaganga-Rupsa-Passur river system is shown in fig. 2. This Figure also indicates the increase in salinity due to the sea level rise along the river system. The salinity long profile along KapotakshiArpangasia river system is shown in fig. 3 .

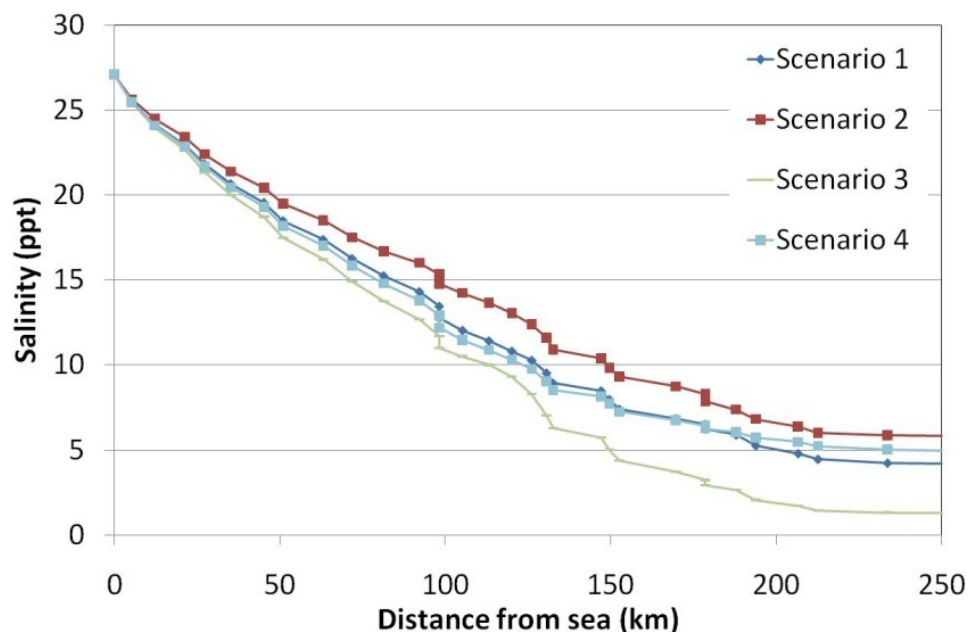

Figure 2: $\quad$ Salinity along Kumar-Nabaganga-Rupsa-Passur river system.

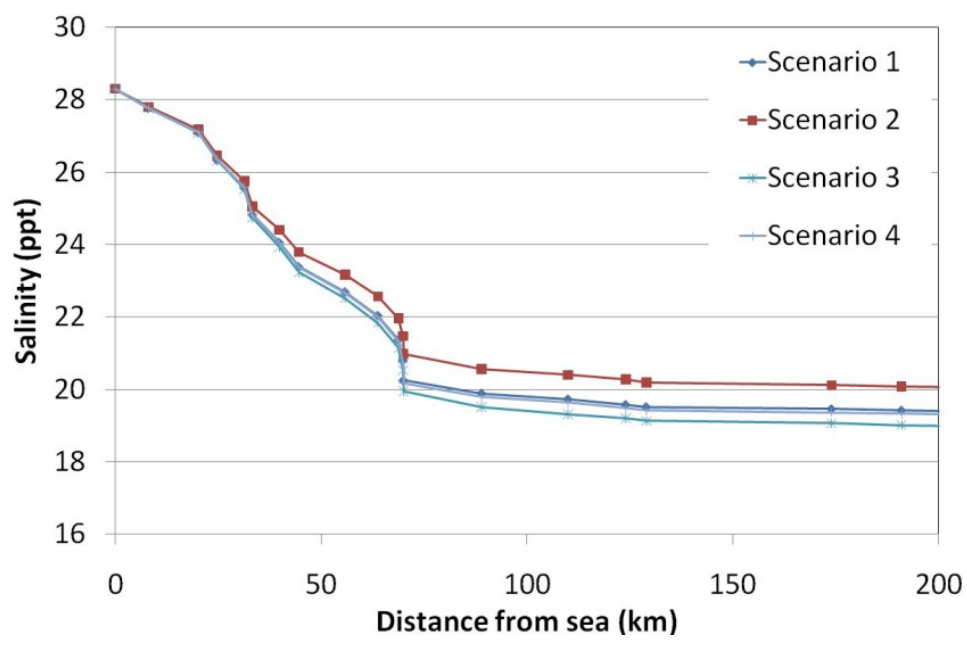

Figure 3: $\quad$ Salinity along Kapotakshi-Arpangasia river system. 
For sea level rise of $59 \mathrm{~cm}$, the $5 \mathrm{ppt}$ and $10 \mathrm{ppt}$ salinity front moved further inland by 25 and $7 \mathrm{~km}$ respectively from present condition. Also the dry period maximum salinity has increased due to sea level rise. The increased salinity has been protected with increased upstream river flow in other scenarios. The simulated salinities at Mongla and Nalianala stations for different scenarios have been shown in Table 3.

Table 3: $\quad$ Simulated maximum salinity for different scenario.

\begin{tabular}{|c|c|c|c|c|}
\hline Station & Scenario 1 & Scenario 2 & Scenario 3 & Scenario 4 \\
\hline Mongla & 15.3 & 16.7 & 13.8 & 14.8 \\
\hline Nalianala & 20.8 & 21.6 & 20.1 & 20.6 \\
\hline
\end{tabular}

From the simulated model results, it is observed that the salinities in the river system have increased due to sea level rise. Again, using increased freshwater system in the upstream station, the previously increased salinity can be reduced and salinity front can be pushed back to downstream.

\section{Conclusion}

Combined use of surface flow and salinity transport in coastal river systems is one of the most significant strategies for optimal development of water resources maintaining the salinity intrusion level within the desirable limit. This requires an assessment of flow and salinity intrusion in the river network. The river flow, surface flow and salinity transport models are coupled and solved interactively to account for the dynamic exchange of flow and solute transport between the rivers and the flood plain.

The results showed intrusion of salinity in South West region due to sea level rise. Sea level rise of $59 \mathrm{~cm}$ will increase salinity at Mongla and Nalianala station by 1.4 and $0.8 \mathrm{ppt}$. However, if minimum flow of $100 \mathrm{~m}^{3} / \mathrm{s}$ and $10 \mathrm{~m}^{3} / \mathrm{s}$ can be maintained at Gorai Railway Bridge and Garaganj station, it will restrict the salinity at Mongla up to a maximum of $14.8 \mathrm{ppt}$. Similarly, maintaining minimum flow of $5 \mathrm{~m}^{3} / \mathrm{s}$ at Jhikargacha will restrict the salinity at Nalianala up to $20.6 \mathrm{ppt}$.

The study focused the salinity impact on river due to sea level rise only. Other consequences of climate change may accelerate or delay the consequences of sea level rise. For example, if droughts become more severe in the future then there will be a reduction in upstream flow. This will further worsen the situation and increase the salinity.

\section{References}

[1] Bashar, K. E. \& Hossain, M. A., Impact of Sea Level Rise on Salinity of Coastal Area of Bangladesh. 9th International River Symposium. Brisbane, Australia, 2006. 
[2] Nobi, N. \& Gupta, A. D., Simulation of regional flow and salinity intrusion in an integrated stream-aquifer system in coastal region: southwest region of Bangladesh. Ground Water, 35(5), pp. 786-796, 1997.

[3] Haque, S. A., Salinity problems and crop production in coastal regions of Bangladesh. Pak. J. Bot., 38(5), pp. 1359-1365, 2006.

[4] Mirza, M. M. Q. \& Sarker, M. H., Effects on water salinity in Bangladesh, in The Ganges water diversion: environmental effects and implications, Water science and technology library, Kluwer Academic Publishers, Netherlands, pp. 81-102, 2005.

[5] Mondal, M. K., Bhuiyan, S. I. \& Franco, D. T., Soil salinity reduction and prediction of salt dynamics in the coastal ricelands of Bangladesh. Agricultural water management, 47(1), pp. 9-23, 2001.

[6] Bhuiyan, M. J. A. N., Dutta, D., Gupta, A. D. \& Babel, M. S., Flood Simulation and Its Socio-Economic Impact Analysis in Meghna Delta, Bangladesh Under Climate Change Conditions. International Symposium on Floods in Coastal Cities under Climate Change Conditions, Bangkok, Thailand, June, 2005, pp.1-10, 2005.

[7] Dutta, D. \& Bhuiyan, M. J. A. N., Flood Characteristics under Changing Climatic Conditions in Meghna Delta, Bangladesh. 16th IASTED International Conference APPLIED SIMULATION AND MODELLING, Palma de Mallorca, Spain, August 29 - August 31, 2007, pp. 162-167, 2007.

[8] Dutta, D., Alam, M. J., Umeda, K., Hayashi, M. \& Hironaka, S., Urban Flood Modeling in Lower Mekong Basin: A Physically Based Distributed Modeling Approach. International Conference on Sustainable Water Resources Management in the Changing Environment of the Monsoon Region, Colombo, Sri Lanka, 2004.

[9] Fischer, H. B., List, E. J., Koh, R. C. Y., Imberger, J. \& Brooks, N. H., MIXING in Inland and Coastal Waters. Academic Press Inc. (London) Ltd, 1979.

[10] Orlob, G. T. (ed.), Mathematical Modelling of Water Quality: Streams, Lakes and Reservoirs. J. Wiley, Chichester, 1983.

[11] Henderson-Sellars, B., Young, P. C., \& Ribeiro da Costa, J., Water quality models: rivers and reservoirs, in Proc. 1988 Int. Symp. On Water Quality Modelling of Agricultural Non-Point Sources; United States Dept of Agriculture, Agricultural Research Service; 1990; Publication No. ARS-81, pp. 381-420, 1990.

[12] Young, P.C., \& Wallis, S.G., Solute transport and dispersion in channels, forthcoming in: K.J. Beven and M.J. Kirby (eds), Channel Networks, J. Wiley, Chichester, 1992.

[13] DHI, MIKE 11 - A Modelling System for Rivers and Channels. Short introduction tutorial. DHI Water and Environment, pp. 5-27, 2003.

[14] Zheng, C. \& Bennette, G. D., Applied Contaminant Transport Modeling, Theory and Practice. Van Nostrand Reinhold, a division of International Thomson Publishing Inc. New York, 1995. 
[15] Tingsanchali, T. \& Karim, M. F., Flood Hazard and Risk Analysis in the Southwest Region of Bangladesh. Hydrological Processes 19(10): pp. 2055-2069, 2005.

[16] Bhuiyan, M. J. A. N. \& Dutta, D., Adaptation Strategies For Sea Level Rise Impact On Coastal Cities: A Case Study, South Western Coastal Region Of Bangladesh. International Symposium on Coastal zones and Climate Change: Assessing the Impacts and Developing Adaptation Strategies, Monash University, Australia, April 12 - 13, 2010, pp. 303-313, 2010.

[17] Stehr, A., Debels, P., Romero, F. \& Alcayaga, H., Hydrological modelling with SWAT under conditions of limited data availability: evaluation of results from a Chilean case study / Modélisation hydrologique avec SWAT en conditions de données peu disponibles: évaluation des résultats d'une application au Chili. Hydrological Sciences Journal, 53(3), pp. 588-601, 2008.

[18] Abu El-Nasr, A., Arnold, J. G., Feyen, J. \& Berlamont, J., Modelling the hydrology of a catchment using a distributed and a semi-distributed model. Hydrol. Processes, 19(3), pp. 573-587, 2005. 